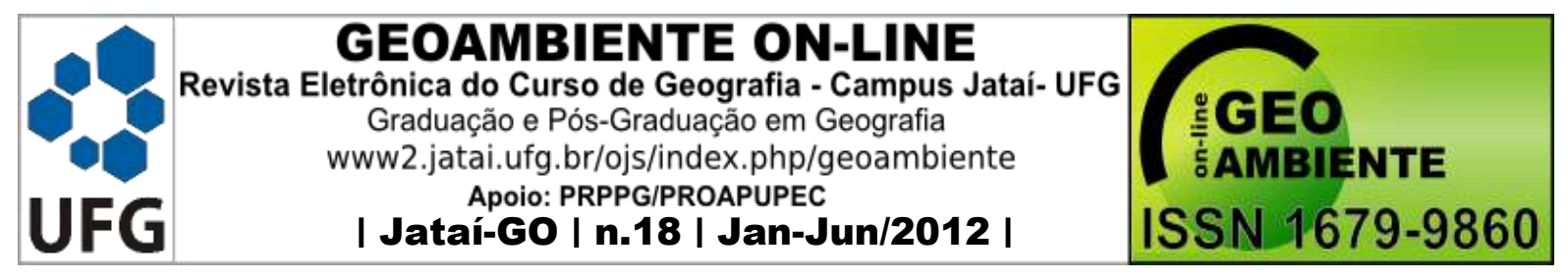

\title{
EXPANSÃO URBANA E PROTEÇÃO AMBIENTAL: RESERVA PARTICULAR DO PATRIMÔNIO NATURAL MUNICIPAL (RPPN) - MANAUS (AM)
}

\author{
Neliane de Sousa Alves ${ }^{1}$, Deivison Carvalho Molinari ${ }^{2}$
}

(1 - Universidade do Estado do Amazonas (UEA), professora, Doutoranda em Geografia Física (USP), e-mail: nsalves@uea.edu.br, 2 - Universidade Federal do Amazonas, professora, Doutorando em Geografia Física (USP), (UFAM), e-mail: molinar@ufam.edu.br)

\section{Resumo}

O presente trabalho tem como objetivo central realizar breve sistematização do processo de criação e implementação de Reservas Particulares do Patrimônio Natural no município de Manaus (AM). Para isto, realizou-se um histórico da evolução urbana visando compreender a gênese dos problemas ambientais; sistematizou-se os marcos regulatórios referentes a proteção ambiental em nível municipal na perspectiva de compreender via legislação como se alicerça a segurança jurídica ambiental no que tange as RPPNs; e, por fim, destacaram-se os critérios (ecológicos, econômicos e políticos institucionais) de implantação e as características de cada RPPN municipal. Os resultados permitem afirmar que existem 6 RPPNs municipais criadas, na qual somente uma, a da Moto Honda apresenta plano de manejo. As impressões sinalizam que as RPPNs constituem em espaços favoráveis a proteção da diversidade biológica permitindo a conectividade de áreas protegidas, auxiliam a proteção da fauna local (como no caso do Sauim de Manaus) e principalmente constituem-se em respostas diretas a isenção fiscal municipais (IPTU VERDE).

Artigo recebido para publicação em 23 de Março de 2011

Artigo aprovado para publicação em 05 de Junho de 2012 


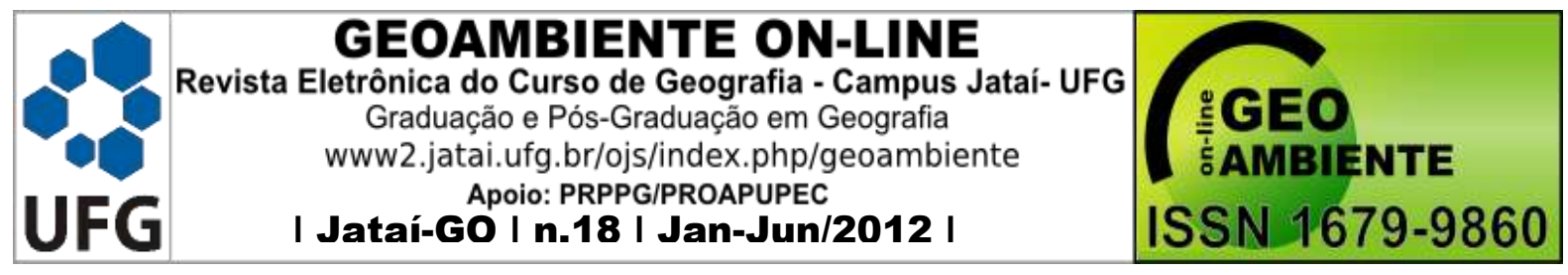

Palavras chaves: Proteção Ambiental, Unidade de Conservação, RPPN, IPTU VERDE e Manaus

\section{Abstract \\ URBAN EXPANSION AND AMBIENT PROTECTION: PARTICULAR RESERVE OF THE MUNICIPAL NATURAL PATRIMONY (RPPN) - MANAUS (AM)}

This paper has as its central objective to do a brief systematization of the process of creation and implementation of private reserves of the natural patrimony of the city of Manaus (AM). To do so, a historic of the urban evolution was made in order to comprehend the root of the environmental problems. The regulatory marcs related to the environmental protection in a more regional level were systemized in the hopes to understand by legislation how does the environmental juridical safety is grounded, in what the RPPN's are concerned. At last, it's featured the criteria (ecologic, economic and politic) of implementation and the characteristics of each local RPPN. The results allow to state that there are 6 RPPN created, of which only one, the Moto Honda one, presents a handling plan. The impressions signalize that the RPPN constitute in favorable locations the protection of the biologic diversity allowing a connectivity of protected areas, they aid in the protection of the local fauna ( like the case of the Saumin of Manaus) and mainly they constitute themselves in direct responses to the local fiscal exemption (IPTU VERDE).

Keyword: Environmental Protection; Protected Areas, RPPN, IPTU VERDE and Manaus.

\section{Résumé}

EXPANSION URBAINE ET PROTECTION ENVIRONNEMENTALE: RÉSERVE PARTICULIÈRE DU PATRIMOINE NATUREL MUNICIPAL (RPPN) - MANAUS (AM)

Cet article vise à présenter une petite systématisation du processus de création et de mise en œuvre des réserves privées du patrimoine naturel dans la ville de Manaus (AM). Pour cela, il 


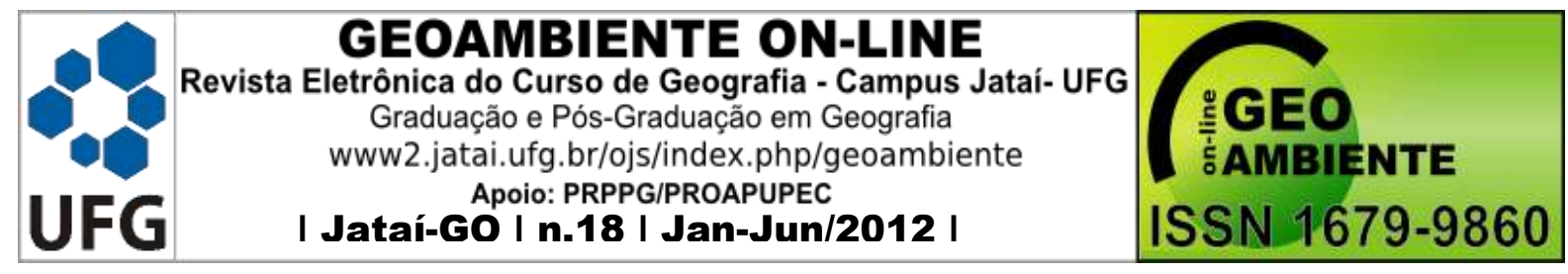

a été réalisé une histoire du développement urbain en visant à comprendre la genèse des problèmes environnementaux : il s'est systématisé les cadres réglementaires relatifs à la protection de l'environnement au niveau municipal afin de comprendre comment suivre la législation est soutenue par la sécurité juridique en ce qui concerne l'environnement RPPNs ; et, finalement, se sont détachés les critères (écologiques, économiques et politiques institutionnels) d'implantation et les caractéristiques de chaque RPPN municipale. Les résultats permettent d'affirmer qui existent 6 RPPNs municipaux créés dans lequel une seule, la entreprise Moto Honda présente un plan de gestion. Impressions indiquent que les réserves privées constituent comme des espaces favorables à la protection de la diversité biologique permettant la connectivité des aires protégées, contribuer à protéger la faune locale (comme dans le cas de Sauim de Manaus) et essentiellement composent réponses directes à l'exemption de taxes fiscales municipales (IPTU VERT).

Mots-clés: protection de l'environnement, Unité de Conservation, RPPN, la taxe foncière (IPTU VERDE), Manaus

\section{INTRODUÇÃO}

A configuração urbana manauara apresentou nas ultimas quatro décadas um crescimento espacial e populacional significativa devido à criação da Zona Franca em meados da década de 1960/70. Este crescimento ocasionou diversas transformações no espaço físico, dentre as quais se destaca a ocupação de áreas legalmente protegidas como as bordas de igarapés (APP) e de barrancos com inclinação acima de $45^{\circ}$, além dos desmatamentos em todas as zonas da cidade, entre outros.

A partir dos problemas sociambientais existentes diversas ações foram e estão sendo tomadas pelo poder público e pela iniciativa privada no sentido de coibir e/ou minimizar a degradação ambiental, uma das formas é a criação de Reservas Particulares do Patrimônio Natural (RPPNs). Diante disso, o presente artigo tem como objetivo central realizar breve 


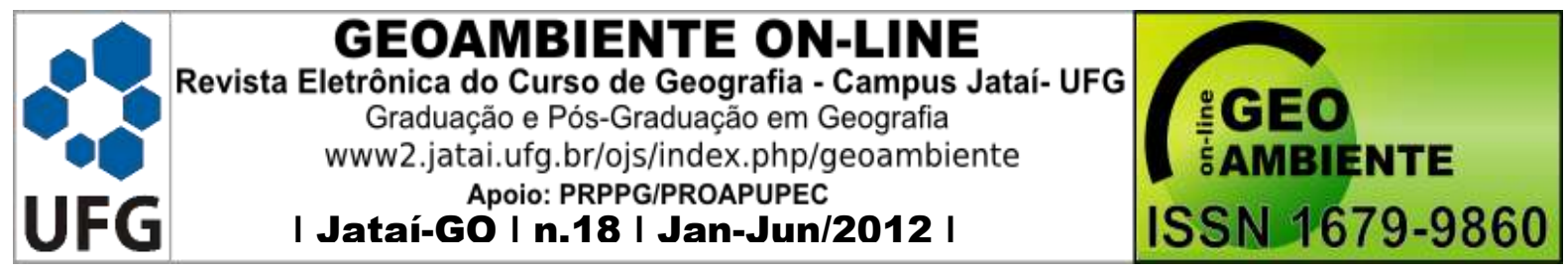

sistematização do processo de criação e implementação de Reservas Particulares do Patrimônio Natural no município de Manaus (AM).

O presente texto está estruturado em 5 partes: a primeira apresenta de forma resumida um histórico da evolução urbana visando compreender a gênese dos problemas ambientais (redução da cobertura vegetal, poluição e assoreamento dos canais fluviais, entre outros); a segunda parte sistematiza os marcos regulatórios referentes a proteção ambiental em nível municipal (Lei Orgânica, Lei $n^{\circ}$ 321/95, Código Ambiental, Resolução $n^{\circ}$ 002/02 do Conselho Municipal de Desenvolvimento e Meio Ambiente - COMDEMA, Plano Diretor, Lei $n^{o}$ 886/2005 referente as RPPNs em Manaus) na perspectiva de compreender via legislação como alicerça-se a segurança jurídica ambiental no que tange as RPPNs em Manaus; a terceira parte trata dos critérios (ecológicos, econômicos e políticos institucionais) de implantação das RPPNs; a quarta parte versa especificamente das RPPNs criadas em Manaus e avalia o estágio de implementação; por fim, a quinta parte denominada de considerações finais sintetiza as impressões sobre os interesses presentes na criação e implementação das RPPNs em Manaus.

\section{EXPANSÃO URBANA DE MANAUS E PROBLEMAS AMBIENTAIS}

Segundo Salati (1990) o desenvolvimento da cidade de Manaus deu-se em três fases: a primeira caracterizada pela chegada do colono português; a segunda, pelo início do arranjo administrativo (como projetos de colonização e desenvolvimento regional); e a terceira, identificada por projetos de integração da Amazônia ao restante do país, assim como pela introdução indústrias, hidroelétricas, entre outras.

A primeira fase (1669 - 1840) caracterizada pelo início da colonização em 1657, quando os colonos portugueses expulsaram os holandeses do estuário do rio Amazonas. Com a finalidade de assegurar a região do rio Negro e Solimões houve a primeira expedição organizada por Bento Maciel Parente, proporcionando a instalação de grupos jesuítas para catequese dos indígenas (BERETTA, 1975). 


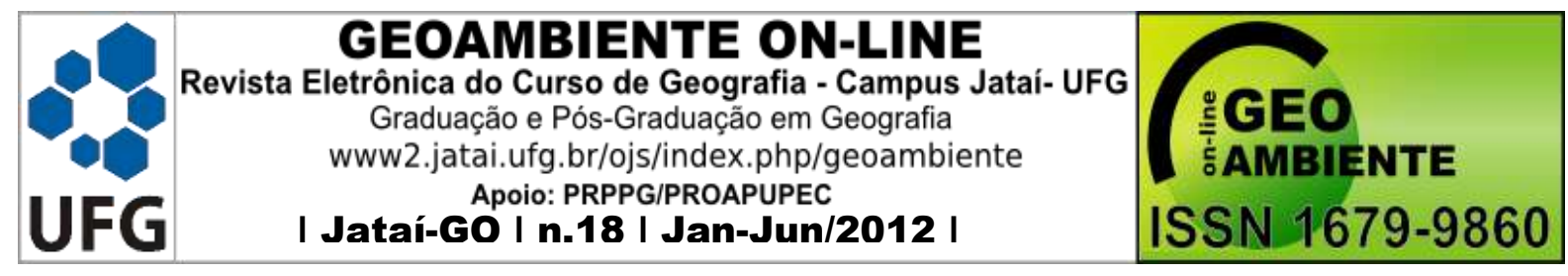

No século XIX o lugar da Barra transformou-se em Vila da Barra do Rio Negro, na qual a capital era Capitania do Rio Negro, logo após foi elevada a Província do Amazonas. Este desenvolvimento político influenciou na funcionalidade administrativa do local e também no crescimento populacional que era de 220 habitantes em 1774 para 4.188 habitantes em 1839 (BERETTA, 1975).

A segunda fase (1840 - 1955) é assinalada pela proclamação da República e pelo aumento populacional. Este rápido e constante crescimento deve-se a transformação econômica com o advento do Ciclo da Borracha, que por sua vez contribuiu de forma significativa para o avanço populacional quanto urbanístico (AB'SABER, 1953). De 1890 a 1920 a população da cidade de Manaus saltara de 10.000 para 75.000 habitantes - caso que se explica pela intensa migração, principalmente de nordestinos, para região. $\mathrm{O}$ crescimento da cidade ocorreu sob o impulso de uma economia de coleta extensiva que dependeu de um mecanismo de circulação moroso ligado exclusivamente aos rios (AB’SABER, 1953).

Vinte anos depois (1940) a população adquiria a cifra de 108.000 habitantes e em 1950, 110.678, evento que intensificou o aparecimento de problemas urbanos, como falta de energia elétrica que inviabilizava a iluminação pública e os transportes coletivos (OLIVEIRA, 2003).

A década de cinqüenta marca o começo da terceira fase de ocupação e impacto sobre a Amazônia. O plano mundial é qualificado como um período de calmaria, já que havia superado a Segunda Guerra Mundial. É nesta fase que o Presidente da República Juscelino Kubitschek incorporou o modelo de desenvolvimento, o Plano de Metas: "cinquenta anos em cinco". A intenção do atual presidente da república era de recuperar o atraso histórico e modernizar o país (PEREIRA, 2006).

Com o estabelecimento da Zona Franca de Manaus (ZFM) a cidade em 1970 apresentava 25,32 $\mathrm{km}^{2}$ e população de 311.622 habitantes, ou seja, o dobro da quantidade populacional do que havia vinte anos antes. 


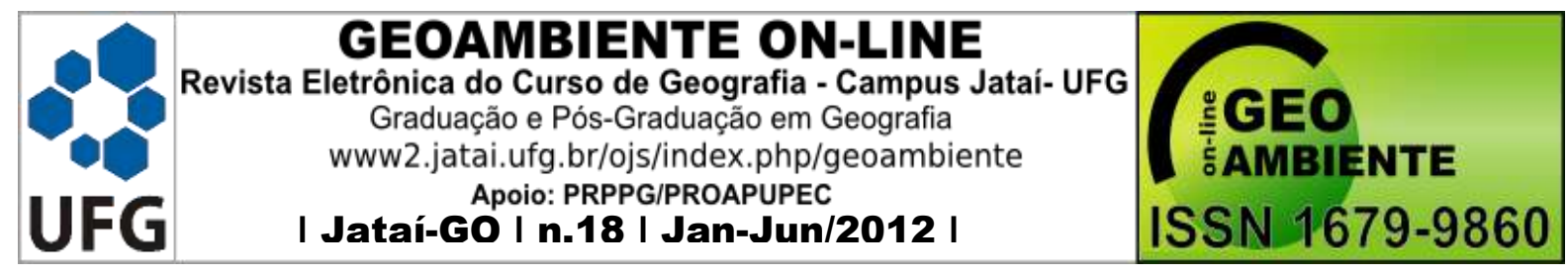

Ribeiro Filho (1999) descreve que a partir dos anos 70 Manaus presenciou um crescimento demográfico significativo (Gráfico 1). Em 1980 a população apresentava 663.392 habitantes, fato proporcionou um inchaço acentuado do espaço urbano, e significativo declínio da população rural - acontecimento que provocou um duplo "vazio demográfico": um no interior do Estado e outro na zona rural de Manaus.

Gráfico 1: Evolução da população de Manaus.

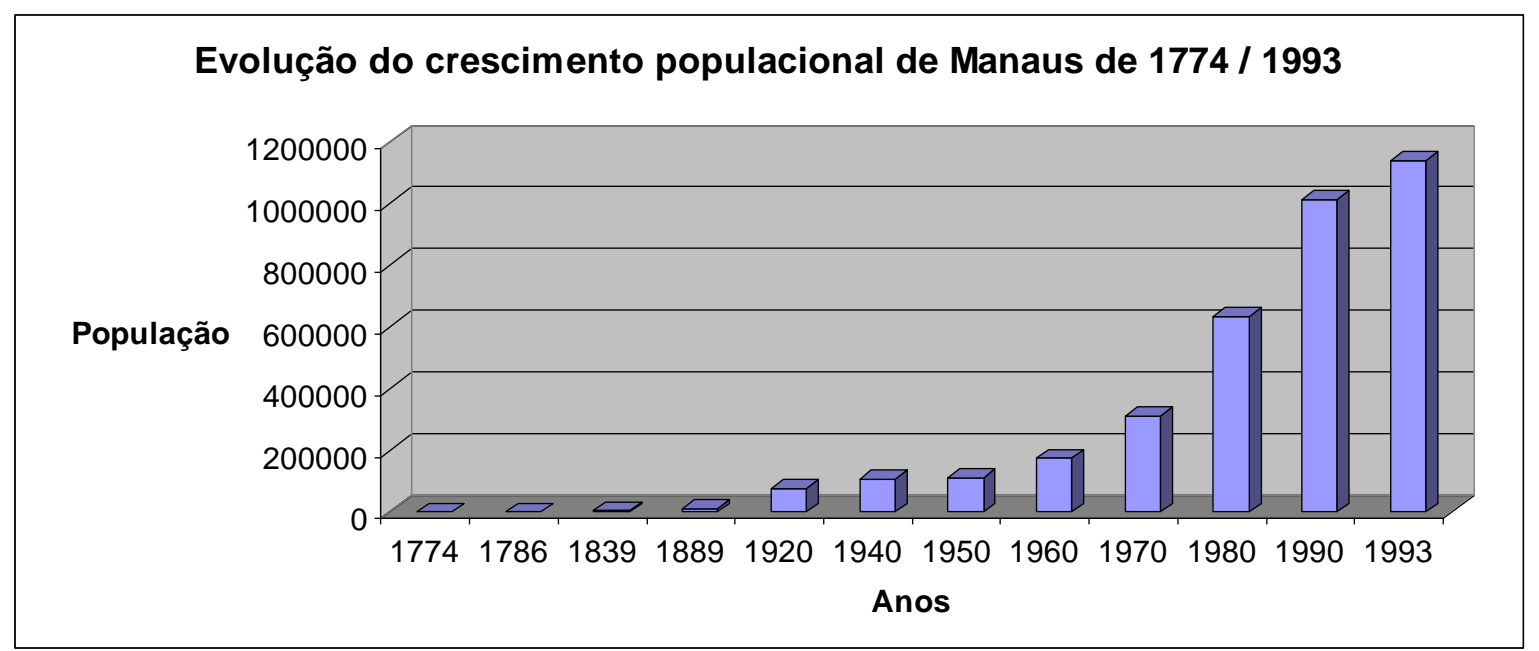

Fonte: RIBEIRO FILHO (1999) adaptado por DONALD (2009).

No ano de 1993, a população manauara era da ordem de 1.138 .159 de habitantes, ocupando uma área de $377,37 \mathrm{~km}^{2}$, o que representava uma densidade populacional de 3.016 hab./km². Em 1995, a população alcança o total de 1.282 .310 habitantes com densidade populacional de 3.398 hab./ $\mathrm{km}^{2}$. De 1970 a 2004, a população cresceu mais de 5 vezes, ou seja, de 311.622 para 1.582.284 habitantes (população estimada pelo IBGE (2000) e a área ocupada pelo sítio urbano teve um aumento de mais de 17,4 vezes, passando de $25,32 \mathrm{~km}^{2}$ para $441,3 \mathrm{~km}^{2}$, o que resulta em uma densidade populacional em torno de $3.585 \mathrm{hab} . / \mathrm{km}^{2}$. Por outro lado, levando em consideração somente a área desmatada da cidade $\left(288,35 \mathrm{~km}^{2}\right)$, a densidade populacional aumenta para 5.487 habitantes por $\mathrm{km}^{2}$ (VIEIRA, 2008).

Ribeiro Filho (1999) afirma que na década de 1980 a cidade cresceu de forma acelerada, originando em muitas zonas municipais ocupações irregulares, produto de 


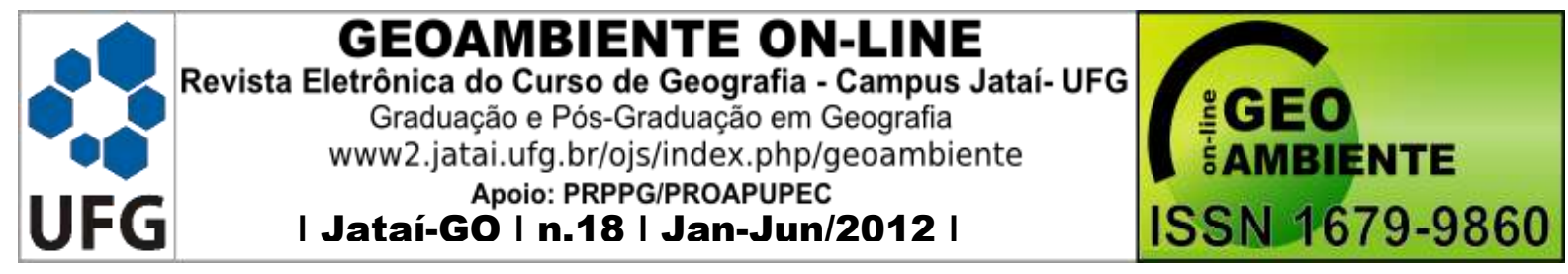

instalações sem planejamento urbanístico. Multiplicando a ocupação próxima a igarapés e dos interflúvios, agravando o problema ambiental e as condições habitacionais na região (RIBEIRO FILHO, 1999).

Um exemplo prático para esta questão é a Zona Leste - 369.056 hab. a mais populosa da cidade. Esta área possui densidade demográfica elevada $\left(5.514,8\right.$ hab./ $\left.\mathrm{km}^{2}\right)$, perdendo somente para Zona Sul que apresenta $9.847,5$ hab. $/ \mathrm{km}^{2}$ (a mais povoada). Devido a estas características favorece ao aparecimento de graves problemas urbanos da cidade tais como: falta de água, luz e saneamento.

Atualmente a cidade de Manaus possui um total populacional de 1.709.010 habitantes (IBGE, 2007). Deste total, aproximadamente $99,5 \%$ da população reside no setor urbano ocupando apenas $4 \%$ da extensão territorial municipal, o que, portanto, releva a elevada concentração demográfica e diversos problemas ambientais.

Dentre as modificações ambientais decorrentes da expansão da malha urbana manaura destaca-se o progressivo e continuo desmatamento da área urbana, seja em seu interior ou em sua borda. De acordo com o SIPAM (2005) houve um aumento das áreas desmatadas nos anos de $1986\left(192,63 \mathrm{~km}^{2}\right), 1995\left(234,19 \mathrm{~km}^{2}\right)$ e $2004\left(288,35 \mathrm{~km}^{2}\right)$ (Figura 1 e Tabela 1). Este problema é assinalado tanto pelo desflorestamento para ocupação irregular quanto àquelas em áreas regularizadas, como construção de conjuntos habitacionais, prédios comerciais, condomínios, entre outros.

As zonas municipais que apresentaram relevante diminuição de suas áreas verdes foram a Leste e Oeste, respectivamente, $47,82 \mathrm{~km}^{2}$ e $26,67 \mathrm{~km}^{2}$, configurando aumento na área desmatada de $100,6 \%$.

Figura 1: Evolução do desmatamento nas zonas 


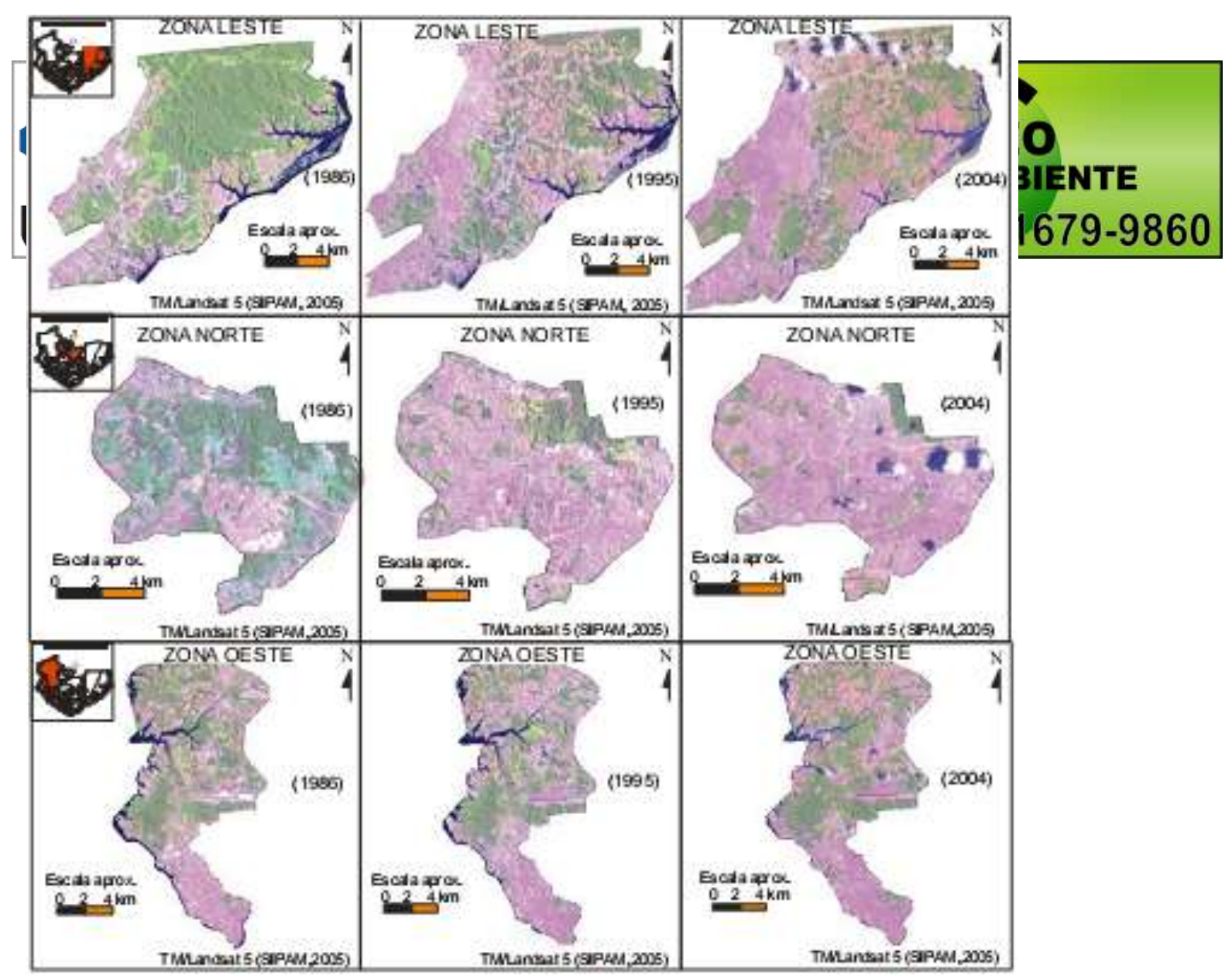

Fonte: SIPAM (2005).

Tabela 1: Perdas de áreas verdes e aumento da área desmatada.

\begin{tabular}{|c|c|c|c|c|c|c|c|c|c|}
\hline \multirow[b]{2}{*}{ ZONA } & \multicolumn{3}{|c|}{$\begin{array}{l}\text { AREA DESMATADA } \\
\text { km }^{2}\end{array}$} & \multicolumn{3}{|c|}{$\begin{array}{l}\text { AंREA VERDE } \\
\text { km }^{2}\end{array}$} & \multicolumn{3}{|c|}{ ÁREA } \\
\hline & 1986 & 1995 & 2004 & 1986 & 1995 & 2004 & $\begin{array}{c}\text { TOTAL } \\
\mathbf{k m}^{2} \\
\end{array}$ & $\begin{array}{l}\text { A.D.; } \\
\mathrm{km}^{2}\end{array}$ & $\%$ \\
\hline LESTE & 47,58 & 69,96 & 95,4 & 115,45 & 93,07 & 67,64 & 163,03 & 47,82 & 100,6 \\
\hline NORTE & 31,65 & 43,96 & 58,3 & 36,59 & 24,29 & 9,93 & 68,24 & 26,67 & 84,2 \\
\hline OESTE & 45,37 & 48,42 & 58,9 & 74,16 & 71,11 & 60,58 & 119,53 & 13,58 & 29,9 \\
\hline $\begin{array}{l}\text { CENTRO- } \\
\text { SUL }\end{array}$ & 24,51 & 28,07 & 31,62 & 11,99 & 8,44 & 4,88 & 36,50 & 7,11 & 29,0 \\
\hline $\begin{array}{l}\text { CENTRO- } \\
\text { OESTE }\end{array}$ & 14,98 & 15,24 & 15,38 & 2,59 & 2,32 & 2,19 & 17,57 & 0,40 & 2,7 \\
\hline SUL & 28,51 & 28,51 & 28,96 & 7,90 & 7,90 & 7,46 & 36,41 & 0,45 & 1,6 \\
\hline TOTAL & 192,60 & 234,19 & 288,63 & 248,68 & 206,12 & 152,65 & 441,28 & 96,03 & 49,86 \\
\hline
\end{tabular}

A.D. (Área desmatada) refere-se a diferença entre a área desmatada até 2004 menos a área desmatada até 1986

Percentual relativo ao aumento da área desmatada de 1986 para 2004

Fonte: SIPAM (2005).

Diante deste quadro, três questões surgem: (a) Qual a legislação responsável pela proteção ambiental no município de Manaus? (b) Qual o nível de aplicação? (c) O que o poder público e a iniciativa privada têm feito para proteger e conservar os recursos naturais em Manaus? Tais questionamentos serão inicialmente discutidos no item a seguir referente aos marcos regulatórios ambientais municipais. 


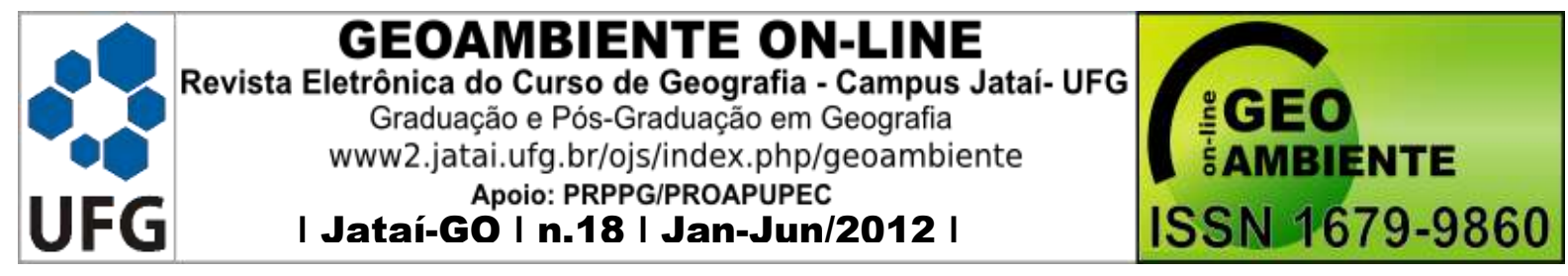

\section{PROTEÇÃO AMBIENTAL: MARCOS REGULATÓRIOS}

A proteção ambiental no município de Manaus tem seu registro na Lei Orgânica do Município - LOMAN (Art. 8 Inc. XII) que especifica como competência do município a preservação da floresta, da fauna e da flora. Na mesma lei o Capítulo II que trata da Política do Meio Ambiente, Art. 296, faculta ao município a criação, por critério próprio, de reservas ecológicas ou a declaração de áreas de relevante interesse ecológico. Inicialmente, nesta lei, foram consideradas áreas de interesse ecológico dentro do município a Ponta Negra, o Tarumã, a Ponte da Bolívia, a Praia do Tupé e a Praia do Amarelinho, na orla do bairro de Educandos, e os igarapés localizados no Município de Manaus.

Estas reservas ecológicas foram destinadas à prestação de atividades de cunho científico e do turismo contemplativo, não sendo permitida qualquer obra ou edificação destinada à exploração econômica, exceto as indispensáveis aos serviços públicos para a sua guarda, segurança e manutenção.

A matéria volta a ser tratada na Lei Municipal $n^{\circ} 321 / 95$ que define e delimita as áreas que constituirão o Sistema Municipal de Unidades de Conservação e cria as Unidades Ambientais do Município de Manaus - UNAs. Para efeito de definição e delimitação as unidades do Sistema Municipal de Unidades de Conservação foram classificadas nas seguintes categorias de manejo: Reserva Ecológica, Reserva Florestal, Reserva Biológica, Reserva de Fauna, Estação Ecológica, Estação Experimental, Monumento Natural, Parque Municipal, Área de Relevante Interesse Ecológico, Jardim Botânico, Horto Florestal e Jardim Zoológico. As UNAs do município foram assim definidas: UNA da Ponta Negra, do Tarumã, da Ponte da Bolívia, do TUPÉ, do Encontro das Águas, da Universidade do Amazonas e a UNA da Praia do Amarelinho.

Os objetivo na implantação e funcionamento das UNAs do Município de Manaus, incluíam: favorecer condições para educação ambiental, recreação em contato com a natureza; 


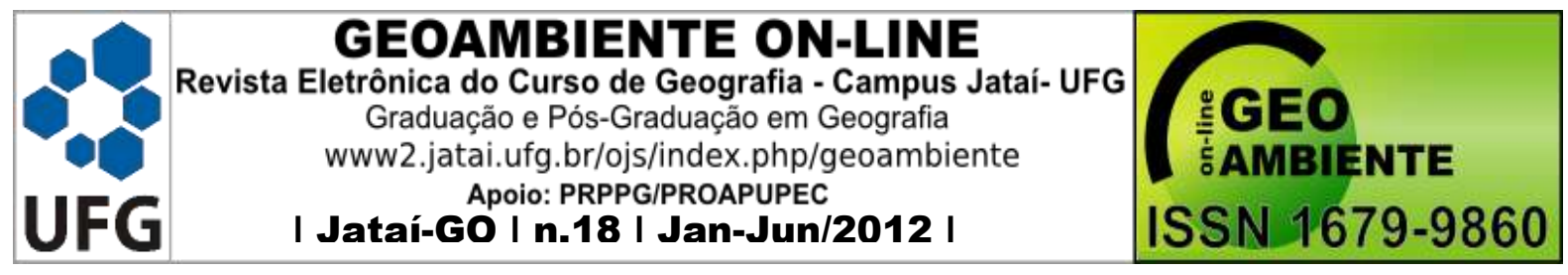

estimular o desenvolvimento regional integrado; preservar a diversidade de ecossistemas naturais; manter a diversidade biológica no território e nas águas; proteger paisagens naturais ou pouco alteradas, de beleza cênica notável; proteger e recuperar recursos hídricos; preservar, provisoriamente, áreas naturais ou pouco alteradas, até que estudos futuros indiquem uma adequada destinação; incentivar o uso sustentável dos recursos naturais. Para atender estes objetivos deveria ser elaborado o zoneamento ecológico-econômico das áreas. A lei também trata das restrições e proibição nas áreas criadas.

O Código Ambiental do Município de Manaus, Lei $n^{\circ}$ 605/2001 também contempla a UCs no Capítulo IV (Dos Espaços Territoriais Especialmente Protegidos), Art.31, Inc. II, definindo para estas Unidades de Conservação a maioria das categorias definidas para as UNAs do Município de Manaus (Lei $n^{\circ}$ 321/95), excetuando a Reserva Florestal e a Estação Experimental. As categorias Refúgio da Vida Silvestre, Reserva de Desenvolvimento Sustentável, Área de Proteção Ambiental e Reserva Particular do Patrimônio Natural, ou seja as RPPNs Municipais, foram incluídas na nova lei ampliando os níveis de categorias das UCs municipais. As unidades de conservação de domínio privado e seu reconhecimento, na forma da lei, pelo Poder Público já é proposto na lei.

A Resolução $n^{\circ}$ 002/2002 do Conselho Municipal de Desenvolvimento e Meio Ambiente - COMDEMA regulamenta o uso das UCs municipais, dentre estas as RPPNs.

As Unidades de Conservação Municipais também estão contempladas no Plano Diretor e Ambiental do Município de Manaus, Lei $n^{\circ}$ 671/02, no Título III, Capítulo I (Das Unidades de Conservação), adotando as categorias definidas no Código Ambiental Municipal. Foram criadas e implementadas a Área de Proteção Ambiental (APA) do Puraquequara e a Reserva de Desenvolvimento Sustentável (REDES) de Jatuarana. Além disso, duas UNAs foram reenquadradas nas categorias definidas no código ambiental e implementadas, a APA do Tarumã/Ponta Negra e a REDES do Tupé. 


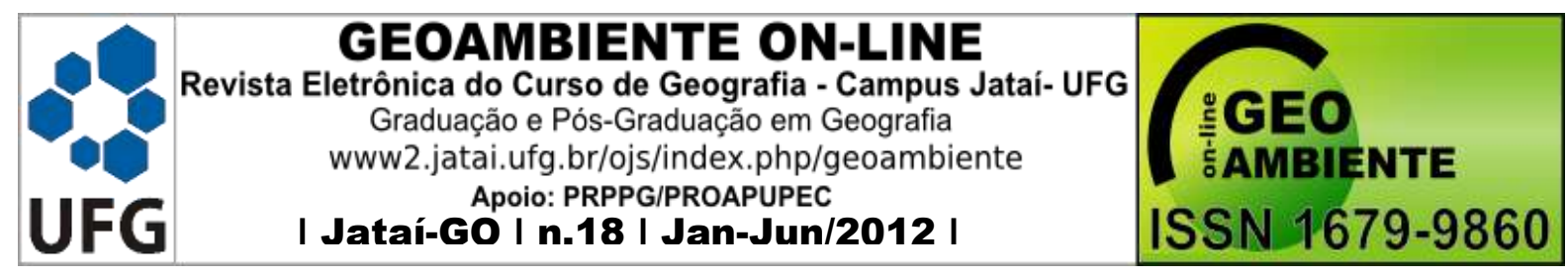

A Câmara Municipal de Manaus aprovou em 2005 a Lei n 886/2005 que dispõe sobre a criação e o reconhecimento das Reservas Particulares do Patrimônio Natural no Município de Manaus.

\subsection{RPPN: MARCO REGULATÓRIO MUNICIPAL - LEI $N^{\circ} 886 / 2005$}

As Reservas Particulares do Patrimônio Natural no Município de Manaus - RPPNs municipais, de acordo com a Lei $n^{\circ} 886 / 2005$ são áreas de domínio privado a ser especialmente protegidas, por iniciativa de seu proprietário, gravadas com perpetuidade, mediante reconhecimento do Poder Público, por ser considerada de relevante importância pela sua biodiversidade, ou pelo seu aspecto paisagístico, ou ainda por suas características ambientais que justifiquem ações de recuperação.

O objetivo das RPPNs é a proteção dos recursos naturais e a conservação da diversidade biológica representativa da região e estas áreas somente poderão ser utilizadas para o desenvolvimento de atividades de cunho científico, cultural, educacional, recreativo e de lazer, observado o objetivo acima. Estas atividades devem ser autorizadas ou licenciadas pela Secretaria Municipal de Meio Ambiente e Sustentabilidade - SEMMAS que é o órgão responsável pelo seu reconhecimento, e deverão ser executadas de forma a não comprometer o equilíbrio ecológico ou colocar em perigo a sobrevivência das populações de espécies ali existentes, observada a capacidade de suporte da área.

A SEMMAS após protocolo de toda a documentação básica pelo proprietário da RPPN realizará vistoria no local e emitirá laudo conclusivo de vistoria do imóvel constando a descrição da área, tipologia vegetal, hidrologia, atributos naturais de destaque, estado de conservação da área, com indicação das eventuais pressões potencialmente degradadoras do ambiente, relacionando as principais atividades desenvolvidas na propriedade, e emitirá parecer quanto à criação da RPPN e, caso favorável, o proprietário firma Termo de Compromisso. O passo seguinte é a homologação do pedido por meio da autoridade competente e a publicação no Diário Oficial do Município do decreto do Prefeito Municipal. O Termo de Compromisso deve ser averbado à margem da inscrição no Cartório de Registro 


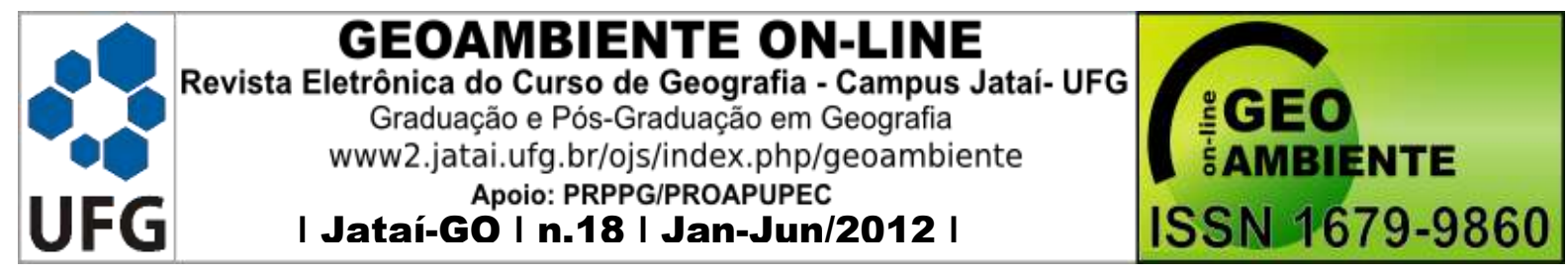

de Imóveis, gravando a área reconhecida como RPPN em caráter perpétuo, nos termos da Lei $\mathrm{n}^{\circ}$. 9.985/00 do Sistema Nacional de Unidades de Conservação - SNUC.

A proteção da RPPN é assegurada pelas autoridades públicas competentes, sem prejuízo do direito de propriedade, exercido pelo titular, na defesa da reserva. Ao proprietário cabe assegurar a manutenção dos atributos ambientais da RPPN; submeter à aprovação da SEMMAS o zoneamento e o plano de utilização (plano de manejo) da reserva; e encaminhar anualmente relatório de situação da reserva e das atividades desenvolvidas. Estas ações podem ser realizadas em cooperação com instituição de ensino e pesquisa local e de entidades ambientalistas credenciadas na SEMMAS.

No que tange ao plano de manejo cabe ao responsável pela administração da RPPN elaborá-lo no prazo de 2 (dois) anos a partir da data de seu reconhecimento pelo município, o plano deverá ser aprovado pela SEMMAS.

Danos ou irregularidades praticadas a RPPN serão objetos de notificação do órgão ambiental ao proprietário, que deverá manifestar-se no prazo estabelecido. Constatada a prática de infração, o infrator estará sujeito às sanções administrativas previstas na legislação vigente, sem prejuízo da responsabilidade civil e penal e, caso a infração seja cometida pelo proprietário, além das sanções previstas, poderá ser suspensa a isenção dos impostos para os períodos posteriores, até que o dano ambiental seja reparado. A lei prevê a redução ou isenção do Imposto sobre a propriedade Predial e Territorial Urbano - IPTU, que deverá ser solicitada pelo proprietário a Secretaria Municipal de Economia e Finanças - SEMEF.

Os proprietários de RPPNs no município de Manaus dispõem na Lei n ${ }^{\circ}$ 1.091/06, referente ao Imposto sobre a propriedade Predial e Territorial Urbano - IPTU, de incentivo fiscal para a criação destas unidades, pois isenta do IPTU a área imóvel reconhecida pelo Poder Público Municipal como RPPN, nos termos da Lei ${ }^{\circ}$ 886/05, devendo o contribuinte observar os procedimentos regulares.

\subsection{PROJETO DE LEI $N^{\circ} 087 / 2009$}




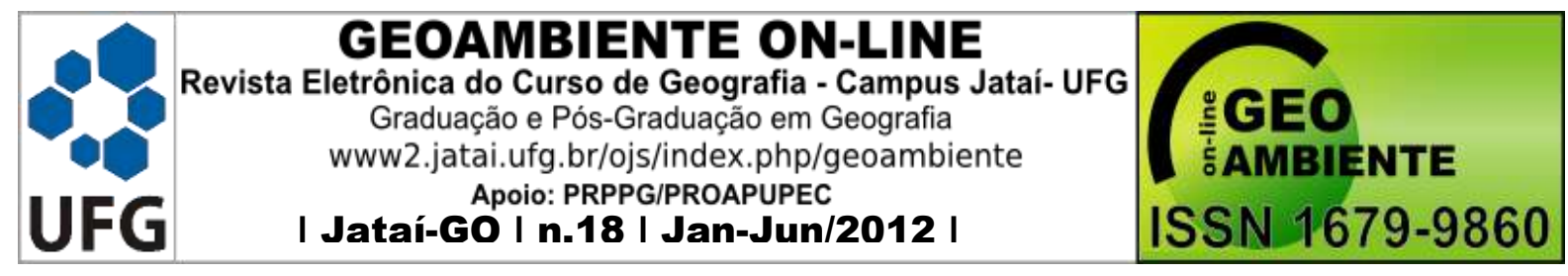

Tramita na Câmara Municipal de Manaus, desde abril do ano de 2011, Projeto de Lei $n^{\circ}$ 087/2009, que institui o Sistema Municipal de Áreas Protegidas no Município de Manaus SMAP estabelecendo critérios e normas para criação, implantação e gestão das áreas ambientalmente protegidas no âmbito do município. O SMAP é composto pelas Unidades de Conservação Municipais, aqui inseridas as RPPNs, cujas categorias, critérios e normas de criação e gestão observarão os dispositivos da Lei $n^{\circ}$ 9.985/2000 do SNUC, e Outros Espaços Especialmente Protegidos compostos por dois grupos: Espaços Especialmente Protegidos de Proteção Integral e de Uso Sustentável. Os Espaços Territoriais de Proteção Integral é composto pelas categorias Áreas de Preservação Permanente e Corredor Ecológico, e as categorias propostas para os Espaços Especialmente Protegidos de Uso Sustentável são as Áreas Verdes Habitacionais, os Fragmentos Florestais Urbanos e as Áreas Protegidas Institucionais.

O SMAP tem como objetivos promover a utilização dos princípios e práticas de conservação da natureza no processo de desenvolvimento; contribuir para a manutenção da diversidade biológica e dos recursos genéticos no município de Manaus; proteger e evitar ameaças às espécies endêmicas, raras ou ameaçadas de extinção no âmbito municipal; contribuir para a preservação e a recuperação da diversidade de ecossistemas naturais; proteger e recuperar recursos hídricos e edáficos; recuperar ou restaurar ecossistemas degradados; valorizar econômica e socialmente a diversidade biológica; favorecer condições e promover a educação e interpretação ambiental, a recreação em contato com a natureza e o turismo ecológico; promover o desenvolvimento sustentável a partir dos recursos naturais; proteger as características relevantes de natureza geológica, geomorfológica, espeleológica, arqueológica, paleontológica e cultural; proporcionar meios e incentivos para atividades de pesquisa científica, e monitoramento ambiental; proteger os recursos naturais necessários à subsistência de populações tradicionais, respeitando e valorizando seu conhecimento e sua cultura e promovendo-as social e economicamente.

A gestão do Sistema Municipal de Áreas Protegidas será executada por um órgão central, no caso a Secretaria Municipal de Meio Ambiente e Sustentabilidade - SEMMAS, e 


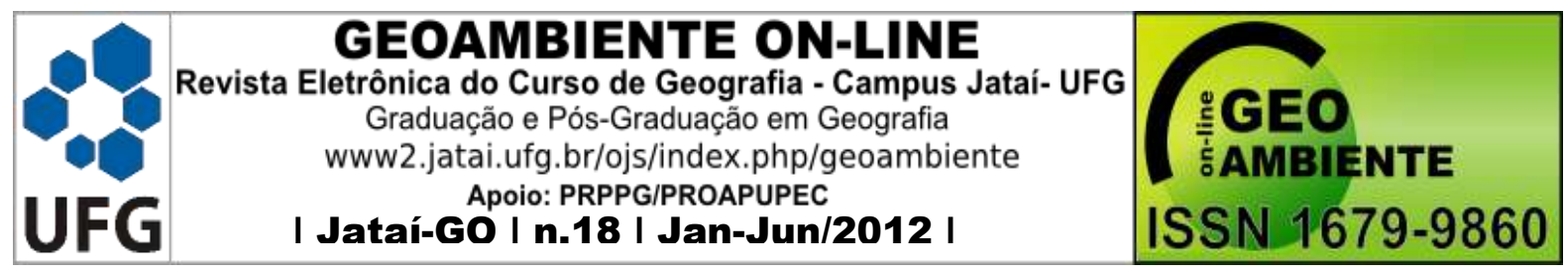

por um órgão supervisor, o Conselho Municipal de Desenvolvimento e Meio Ambiente COMDEMA. A lei também prevê isenção de IPTU para as RPPNs localizadas no perímetro urbano conforme a Lei $n^{\circ} 1.091 / 06$, ao passo que as infrações e penalidades observarão a legislação vigente.

\section{RPPN: CRITÉRIOS DE SELEÇÃO}

De acordo com Morsello (2001) existem três aspectos e/ou critérios para concepção de uma Reserva Particular do Patrimônio Natural (RPPN): ecológico, econômico e politicoinstitucional.

No que tange aos aspectos ecológicos responsáveis pela criação de uma RPPN destacam-se a necessidade de proteção da biodiversidade existente em todos os seus níveis (espécie, comunidades e ambiente) e também devido a presença de espécie endêmica e rara. A criação de RPPNs seguindo critérios ecológicos deve levar em conta duas características: distribuição espacial e a configuração (design).

A distribuição espacial deve ser condicionada a representatividade daquela área a ser delimitada no sistema de reserva, em outras palavras, o modo como o conjunto de áreas protegidas é capaz de representar a biota de certa região, para alcançar o objetivo de conservação da biodiversidade, no sentido de, compensar indevidos (problemas e/ou impactos) causados nas áreas particulares adjacentes (MORSELLO, 2001). Este autora destaca ainda que as unidades de conservação (UCs) públicas por serem insuficientes no estabelecimento de fluxos gênico e migração de fauna, reduze-se significativamente o isolamento entre espécies quando se criam RPPNs entre duas ou mais UCs públicas. Portanto, as RPPNs serviriam como elo ou corredor entre duas ou mais UCs públicas.

Por outro lado, a configuração da RPPN baseia-se no tamanho e na forma que devem ser definidas de acordo com critérios específicos, como por exemplo, a presença de espécie endêmica ou uma espécie rara. 


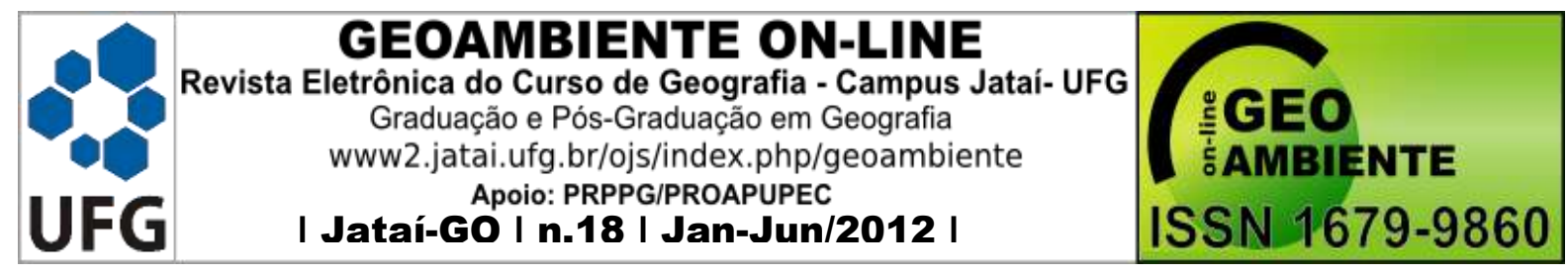

Os aspectos econômicos importantes na criação de uma RPPN estão atrelados a geração de divisas com a atividade turística e ecoturísticas, além das isenções fiscais do Imposto Territorial Rural (ITR), por exemplo, ou o ICMS Ecológico e o IPTU Verde existentes em algumas cidades, como Manaus. Desta forma, as RPPNs surgem como alternativas de gestão para o poder público, pois é mais interessante para os gestores administrarem as UCs criadas do que criar outras, além disso, os gastos com qualificação e manutenção de recursos humanos nessas UCs acabam favorecendo que o poder público estimule via redução de imposto a iniciativa privada a preservar áreas criando as RPPNs.

Por ultimo, os aspectos políticos institucionais responsáveis pela criação de RPPNs estão associados aos interesses dos atores sociais (gestores municipais, empresários, população local, entre outras), para a criação de uma UC. Em tese, a criação de UCs resulta do consenso dos diversos atores sociais locais. No entanto, sabe-se que nem sempre é fácil criar uma UC pública devido as atividades socioeconômicas e culturais já estabelecidas, em muitos casos geram conflitos de territorialidade de difícil solução, desta forma, a RPPN surge como uma "válvula de escape" no sentido de atenuar tais conflitos, de forma, a unir os interesses do proprietário e do poder público em preservar determinada área.

\section{RPPNS MUNICIPAIS}

As Reservas Particulares do Patrimônio Natural Municipais estão estabelecidas conforme o Código Ambiental do Município de Manaus e sua criação e reconhecimento estabelecidas na Lei $n^{\circ}$. 886/05. Existem atualmente 06 (seis) RPPNs municipais criadas e reconhecidas, totalizando 218,13 hectares de áreas protegidas privadas na zona urbana e rural, destas somente a RPPN da Moto Honda apresentou o plano de manejo (Figura 2). Após a aprovação da Lei $n^{\circ}$. 1.091/06 referente ao "IPTU VERDE” o número de RPPNs municipais criadas aumentou consideravelmente de 01(reserva da Moto Honda) para 06, conforme observado na tabela 2 .

Figura 2. Localização das RPPNs do Município de Manaus. 


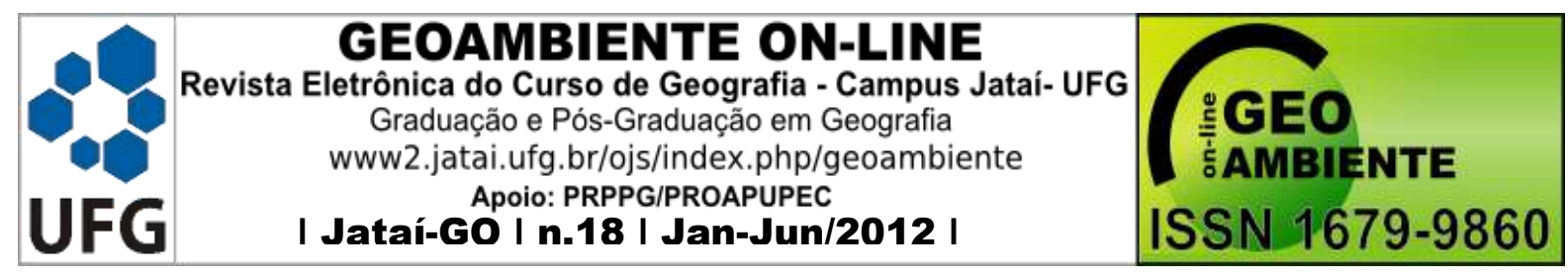

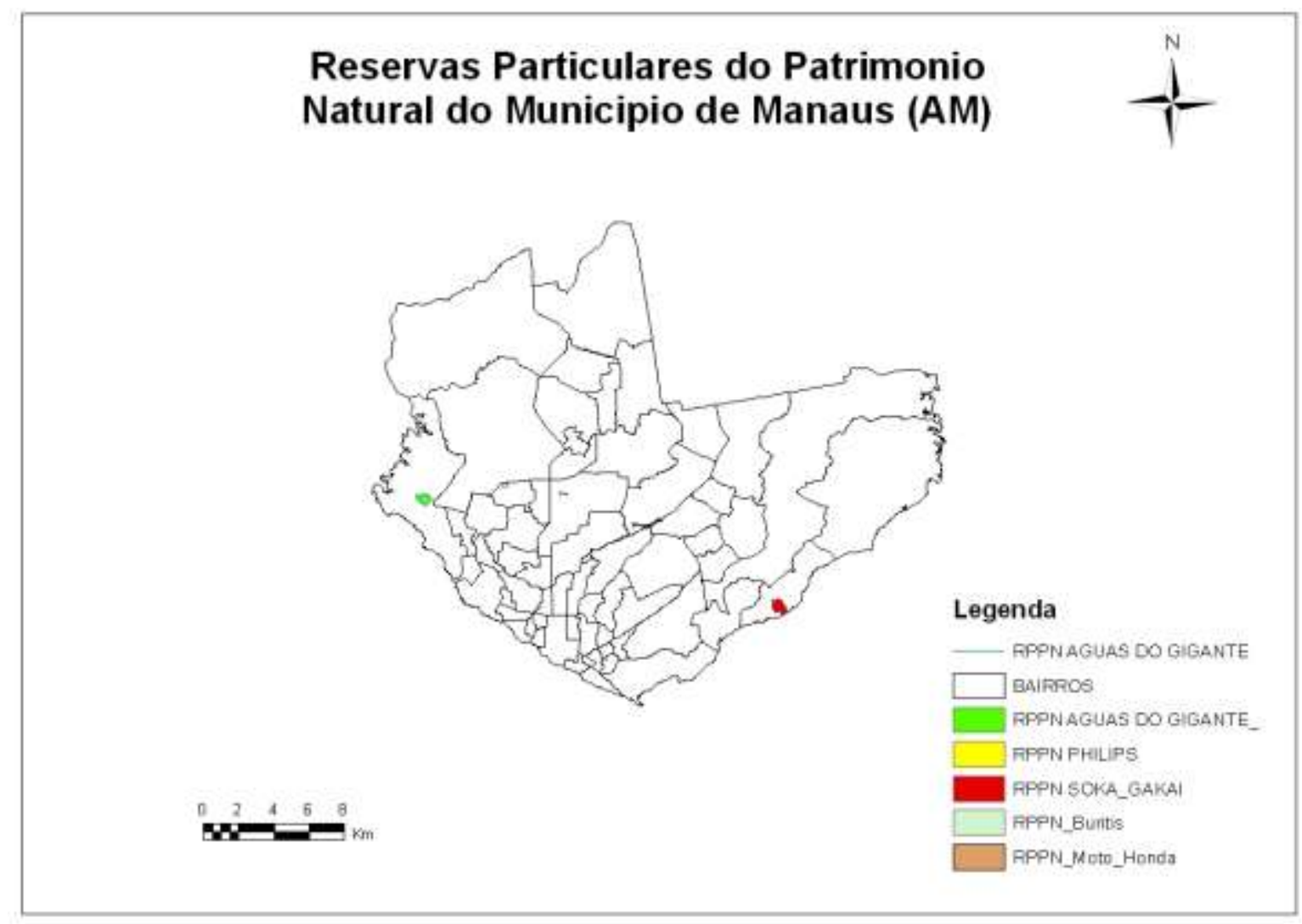

Tabela 2: RPPNs Municipais

\begin{tabular}{|c|c|c|c|c|}
\hline $\begin{array}{c}\text { Espaço } \\
\text { Protegido }\end{array}$ & $\begin{array}{c}\text { Área } \\
\text { Total } \\
\text { (hectares) } \\
\end{array}$ & Localização & Proprietário & $\begin{array}{l}\text { Instrumento de } \\
\text { Criação }\end{array}$ \\
\hline $\begin{array}{l}\text { Reserva da } \\
\text { Moto Honda }\end{array}$ & 16,4 & Área urbana & $\begin{array}{l}\text { Moto Honda da } \\
\text { Amazônia } \\
\text { Ltda. }\end{array}$ & $\begin{array}{l}\text { Decreto Municipal } \\
\mathrm{n}^{\circ} .8 .501 \text { de } 05 \text { de } \\
\text { junho de } 2006\end{array}$ \\
\hline $\begin{array}{c}\text { Reserva dos } \\
\text { Buritis }\end{array}$ & 5,7 & Área urbana & $\begin{array}{l}\text { Francisco de } \\
\text { Paula Castilho } \\
\text { Pereira }\end{array}$ & $\begin{array}{l}\text { Decreto Municipal } \\
n^{\circ} .9 .243 \text { de } 03 \text { de } \\
\text { setembro de } 2007\end{array}$ \\
\hline $\begin{array}{l}\text { Reserva } \\
\text { Norikatsu } \\
\text { Miyamoto }\end{array}$ & 76,9 & Área rural & $\begin{array}{l}\text { Norikatsu } \\
\text { Miyamoto }\end{array}$ & $\begin{array}{l}\text { Decreto Municipal } \\
\mathrm{n}^{\circ} .9 .503 \text { de } 06 \text { de } \\
\text { março de } 2008\end{array}$ \\
\hline $\begin{array}{c}\text { Reserva Águas } \\
\text { do Gigante }\end{array}$ & 35,1 & Área urbana & $\begin{array}{l}\text { T. Loureiro } \\
\text { Corretora de } \\
\text { Imóveis Ltda. }\end{array}$ & $\begin{array}{l}\text { Decreto Municipal } \\
\mathrm{n}^{\circ} .9 .645 \text { de } 27 \text { de } \\
\text { junho de } 2008\end{array}$ \\
\hline $\begin{array}{c}\text { Reserva Nazaré } \\
\text { das Lages }\end{array}$ & 52,05 & Área urbana & $\begin{array}{l}\text { Associação } \\
\text { Brasil SGI }\end{array}$ & $\begin{array}{l}\text { Decreto Municipal } \\
\mathrm{n}^{\circ} .9 .844 \text { de } 22 \text { de } \\
\text { dezembro de } 2008\end{array}$ \\
\hline $\begin{array}{l}\text { Reserva do Sítio } \\
\text { Bons Amigos }\end{array}$ & 31,98 & Área rural & $\begin{array}{c}\text { Marcos } \\
\text { Antônio dos }\end{array}$ & $\begin{array}{l}\text { Decreto Municipal } \\
\mathrm{n}^{\circ} .9 .854 \text { de } 26 \text { de }\end{array}$ \\
\hline
\end{tabular}




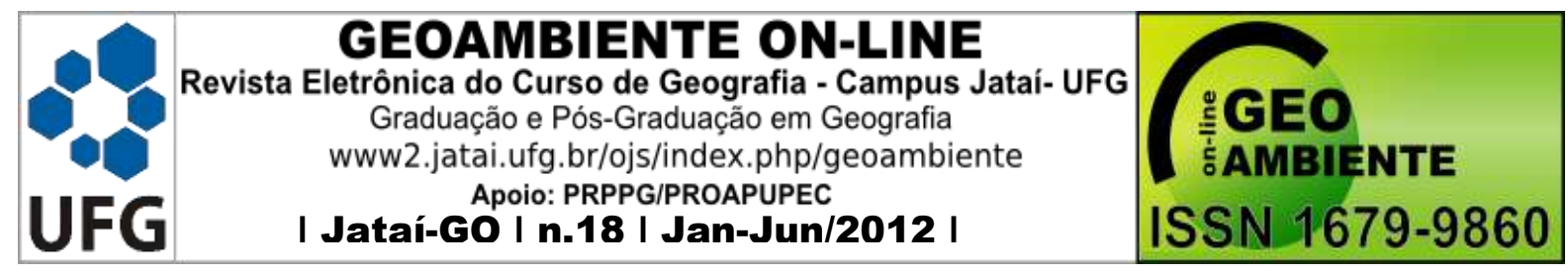

\begin{tabular}{lcc} 
& Santos & dezembro de 2008 \\
\hline Fonte: SEMMAS (2009) & &
\end{tabular}

\section{RPPN Reserva da Moto Honda:}

A RPPN da Moto Honda é a primeira unidade de conservação particular criada no município de Manaus, por meio do Decreto Municipal n 8.501 de 05 de junho de 2006, com o objetivo de proteger e preservar os recursos naturais e a diversidade biológica da região de Manaus, e com a proposta de uma área aberta à visitação pública e a promoção de atividades de cunho científico (pesquisas), educação ambiental e práticas esportivas, protegendo o equilíbrio ecológico e a preservação das espécies. A RPPN com área de 16,4 hectares, de propriedade da Moto Honda da Amazônia Ltda., constitui parte integrante do imóvel denominado Cachoeira Grande.

O plano de manejo apresentado sugeriu no seu zoneamento que a totalidade da RPPN seja zona de proteção integral, sendo previsto dois programas: proteção a fauna e implantação de viveiro florestal.

O programa de proteção a fauna prevê as seguintes atividades: monitoramento das populações existentes; desenvolvimento de estudos e monitoramento, especialmente para a espécie Sauim de Manaus (Saguinus bicolor), espécie endêmica da região de Manaus e ameaçada de extinção; identificação, cadastro e monitoramento dos animais silvestres. Apesar das propostas no âmbito do programa o diagnóstico da fauna não subsidia estas atividades, conforme parecer técnico da SEMMAS.

O programa de implantação de viveiro tem como objetivo a produção de mudas para a recuperação de matas ciliares, tanto na área da RPPN, quanto em outras áreas no entorno da reserva.

Apesar do plano de manejo propor a visitação pública na RPPN, não foi proposto nenhum programa de visitação, sendo somente apresentadas regras básicas de visitação como 


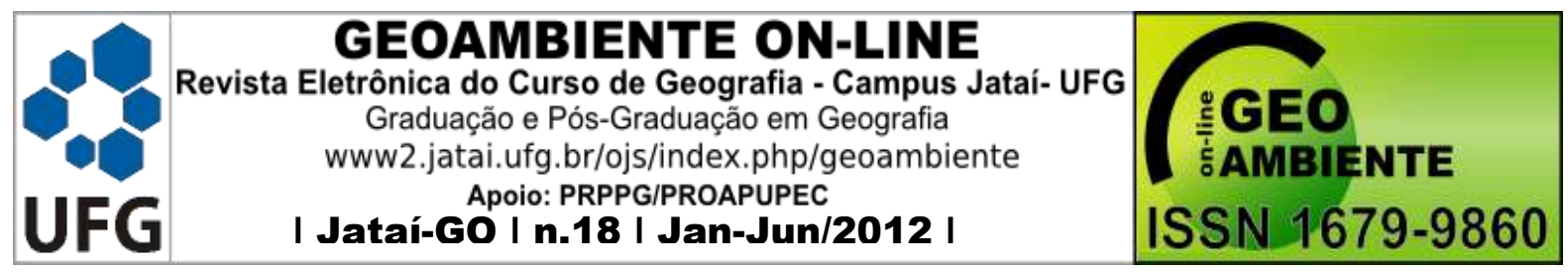

não produzir fogo, não jogar lixo e evitar a aproximação das áreas de reprodução dos animais, dentre outras.

\section{RPPN Reserva dos Buritis}

A RPPN Reserva dos Buritis, criada pelo Decreto Municipal $n^{\circ} 9.243$ de 03 de setembro de 2007, localiza-se na área urbana do município com área de $57.544,13 \mathrm{~m}^{2}$ e perímetro de $1.053,44 \mathrm{~m}$, no bairro da Redenção, na Zona Oeste da cidade, próximo ao Aeroporto Internacional Eduardo Gomes. A RPPN tem como objetivo proteger e preservar os recursos naturais e conservar a biodiversidade da área e, dentre as atividades a serem desenvolvidas está incluída a recuperação de parte da área que se encontrava degradada quando da criação da RPPN. A administração da RPPN é de responsabilidade do proprietário, o Sr. Francisco de Paula Castilho Pereira. De acordo com relatório interno da SEMMAS a área possui igarapés, nascentes, e representantes da fauna local incluindo o Sauim de Manaus (Saguinus bicolor) e conectividade com o fragmento florestal do Aeroporto Internacional Eduardo Gomes.

\section{RPPN Reserva Norikatsu Miyamoto}

A RPPN Reserva Norikatsu Miyamoto localiza-se na AM-010 Km 37, Ramal do Leão, na zona rural da cidade de Manaus. A reserva, de propriedade do Sr. Norikatsu Miyamoto e criada pelo Decreto Municipal $n^{\circ} 9.503$ de 06 de março de 2008, ocupa uma área de $769.501,59 \mathrm{~m}^{2}$ com perímetro de $4.375,17 \mathrm{~m}$ e tem como objetivo básico garantir a proteção integral dos ecossistemas naturais e proteger recursos genéticos da flora e da fauna, especialmente o primata Sauim de Manaus (Saguinus bicolor), possibilitando a realização de pesquisas científicas e o desenvolvimento de atividades de educação e interpretação ambiental, de recreação em contato com a natureza e turismo ecológico.

\section{RPPN Reserva Águas do Gigante}

A Reserva Águas do Gigante possui área de 35,11 hectares com perímetro de $2.855,52 \mathrm{~m}$ de propriedade de T. Loureiro Corretora de Imóveis Ltda. constituindo parte 


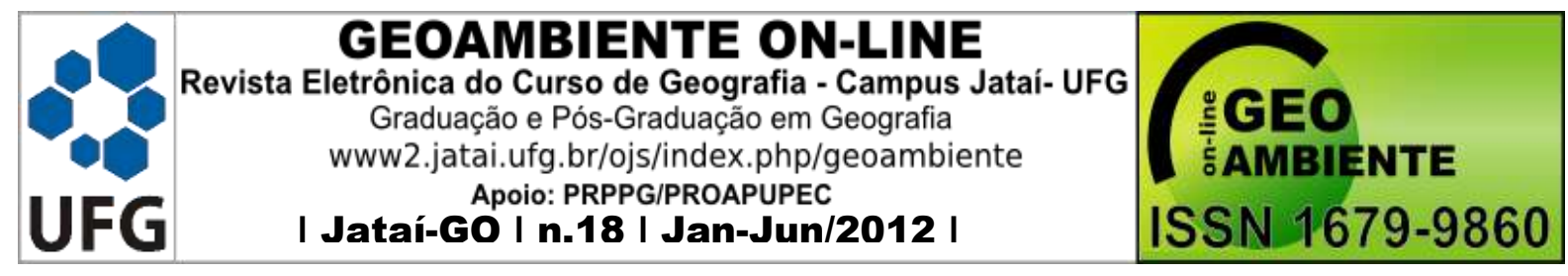

integrante do imóvel denominado Itapuranga IV. A RPPN, criada pelo Decreto Municipal n ${ }^{\circ}$ 9.645 de 27 de junho de 2008, tem como objetivo proteger e preservar integralmente o ecossistema natural, proporcionar refúgio para a fauna e flora local e proteger as nascentes e áreas de preservação permanente existentes em seu interior. Na RPPN somente é permitida a realização de pesquisas científicas, atividades de educação e interpretação ambiental, de recreação em contato com a natureza e de turismo ecológico, garantindo acesso ao público de acordo com suas regras de uso e visitação. A área apresenta aspectos ecológicos relevantes como 02 (duas) nascentes importantes do Igarapé do Gigante e uma diversidade faunística que inclui espécies como o Sauim de Manaus (Saguinus bicolor), preguiça Bentinha (Bradypus tridactylus), preguiça Real (Cholaepus didactylus), Tamanduaí (Cyclopes didactylus) e Tatugalinha (Dasypus novemcinctus), além de aves, roedores, répteis e anfíbios.

\section{RPPN Nazaré das Lajes}

Esta RPPN foi reconhecida pelo município de Manaus, na forma da lei, por meio do Decreto $n^{\circ} 9.884$ de 22 de dezembro de 2008, tendo sido criada pela Portaria $n^{\circ}$ 049/95 IBAMA. Esta se localiza na área urbana do município, com área de 52,05 ha, de propriedade da Associação Brasil SGI, e representada legalmente pelo Sr. Charlles Likiyasu Osawa da Silva. A área de grande relevância ecológica, já reconhecida pelo Poder Público federal através da portaria IBAMA supracitada, tem como objetivo proteger e preservar integralmente o ecossistema natural, proporcionar refúgio para a fauna e flora local, proteger as nascentes e áreas de preservação permanente existentes em seu interior. Nesta RPPN somente é permitida a realização de pesquisas científicas, atividades de educação e interpretação ambiental, de recreação em contato com a natureza e de turismo ecológico, sendo o proprietário o seu administrador direto, conforme as disposições constantes na Lei Municipal $n^{\circ}$ 886/05.

\section{RPPN Reserva do Sítio Bons Amigos}

A Reserva do Sítio Bons Amigos foi criada pelo Poder Público municipal através do Decreto $n^{\circ}$ 9.854, de 26 de dezembro de 2008. Esta RPPN está localizada na BR-174 km 15, Ramal DNER, na zona rural da cidade de Manaus, de propriedade e administração do Sr. 


\begin{tabular}{|c|c|c|}
\hline & $\begin{array}{l}\text { GEOAMBIENTE ON-LINE } \\
\text { Eletrônica do Curso de Geografia - Campus Jataí- U } \\
\text { Graduacăo e Pós-Graduacăo em Geografia } \\
\text { www2.jatai.ufg.br/ojs/index.php/geoambiente } \\
\text { Apoio: PRPPG/PROAPUPEC } \\
\text { | Jataí-GO I n.18 | Jan-Jun/2012 | }\end{array}$ & ISSN $1679-9860$ \\
\hline
\end{tabular}

Marcos Antônio dos Santos, ocupando uma área de 31,9748 ha com perímetro de 3.153,95 m e tem como objetivo básico garantir a proteção integral dos ecossistemas naturais e proteger recursos genéticos da flora e da fauna, especialmente o Primata Sauim de Manaus (Saguinus bicolor), possibilitando a realização de pesquisas científicas e o desenvolvimento de atividades educação e interpretação ambiental, de recreação em contato com a natureza e de turismo ecológico

\section{CONSIDERAÇÕES FINAIS}

Dado os problemas ambientais de Manaus decorrentes do crescimento urbano e populacional caracterizado por modificações da paisagem, seja pela redução da cobertura vegetal, seja pela poluição e/ou assoreamento dos igarapés justificam a criação de UCs municipais visando mitigar as pressões impostas as áreas ainda preservadas ou que tenham recebido um grau mínimo de intervenção humana.

Neste sentido as RPPNs Municipais constituem espaços favoráveis a proteção da diversidade biológica permitindo a conectividade de áreas protegidas como é o caso da RPPN Reserva dos Buritis com o fragmento florestal do aeroporto, e a RPPN da Moto Honda que está inserida no Corredor Ecológico do Mindú. Outro aspecto relacionado a proteção da fauna local é que todas as RPPNs buscam preservar a espécie endêmica Sauim de Manaus (Saguinus bicolor).

A isenção do IPTU para as áreas reconhecidas pelo Poder Público Municipal como RPPNs, estimulou a criação desses espaços protegidos visto que das seis unidades existentes, cinco datam após a lei do IPTU VERDE sinalizando, portanto, que as RPPNs Municipais possuem um forte apelo econômico.

\section{REFERÊNCIAS}

AB'SABER, A. N. A cidade de Manaus. In: Boletim Paulista de Geografia. São Paulo: EUSP, 1953. 


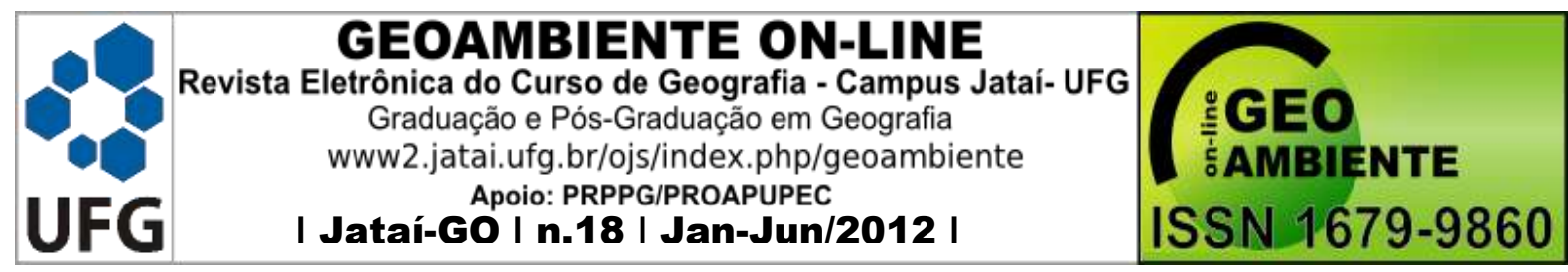

BRASIL. LEI N 9.985 de 18 de junho de 2000. Institui o Sistema Nacional de Unidades de Conservação (SNUC). Diário Oficial da República Federativa do Brasil, Poder Executivo, Brasília, DF. Disponível em: http://www.planalto.gov.br/ccivil/leis/L9985.htm. Acesso em jun.2009.

BERETTA, P. L. Manaus: notas de geografia urbana. In: Boletim Geográfico. Rio de Janeiro, 1975.

DONALD, A. R.; DIRANE, A. C. M.; MOLINARI, D.C. Áreas de risco a Voçorocamento Nova Vitória (Manaus - AM). XIII SIMPÓSIO NACIONAL DE GEOGRAFIA FISICA APLICADA. Viçosa, 2009

IBGE - Instituto Brasileiro de Geografia e Estatística. (2000). Disponível em http://www.ibge.gov.br/censodemográfico. Acesso em 13 de março de 2009.

COMDEMA - Conselho Municipal de Desenvolvimento e Meio Ambiente. Resolução ${ }^{\circ}$ 002/2002. Secretaria Municipal de Meio Ambiente, PMM, Manaus, AM, 2002.

MANAUS. Decreto Municipal $n^{\circ}$. 8.501 de 05 de junho de 2006. Diário Oficial do Município de Manaus, Poder Executivo, Manaus, AM, 08 jun. 2006.

MANAUS. Decreto Municipal $n^{\circ} .9 .243$ de 03 de setembro de 2007. Diário Oficial do Município de Manaus, Poder Executivo, Manaus, AM, 12 set. 2007.

MANAUS. Decreto Municipal $n^{\circ} .9 .503$ de 06 de março de 2008. Diário Oficial do Município de Manaus, Poder Executivo, Manaus, AM, 18 nov. 2008.

MANAUS. Decreto Municipal $n^{\circ} 9.645$ de 27 de junho de 2008. Diário Oficial do Município de Manaus, Poder Executivo, Manaus, AM, 02 jul. 2008.

MANAUS. Decreto Municipal $n^{\circ} .9 .844$ de 22 de dezembro de 2008. Diário Oficial do Município de Manaus, Poder Executivo, Manaus, AM, 24 dez. 2008. 


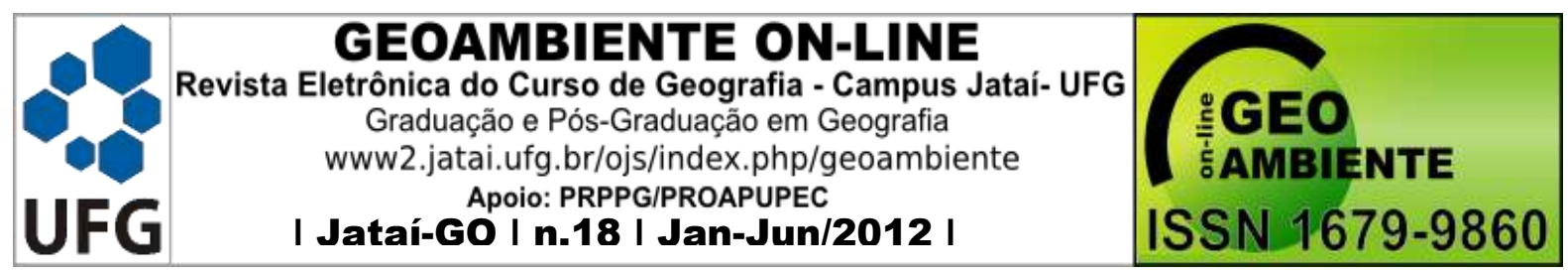

MANAUS. Decreto Municipal $n^{\circ} .9 .854$ de 26 de dezembro de 2008. Diário Oficial do Município de Manaus, Poder Executivo, Manaus, AM, 30 dez. 2008.

MANAUS. Lei $n^{\circ}$ 321, de 20 de dezembro de 1995. Diário Oficial do Município de Manaus, Poder Executivo, Manaus, AM, 31 jan. 1996.

MANAUS. Lei $n^{\circ} 605$ de 24 de julho de 2001. Código Ambiental do Município de Manaus. Secretaria Municipal de Meio Ambiente. PMM, Manaus, AM, 2001.

MANAUS. Lei $n^{\circ}$ 671, de 04 de novembro de 2002. Plano Diretor do Município. Câmara Municipal de Manaus, Manaus, 2006.

MANAUS. Lei $n^{\circ}$ 886, de 14 de outubro de 2005. Diário Oficial do Município de Manaus, Poder Executivo, Manaus, AM, 18 out. 2005.

MANAUS. Lei $n^{\circ}$ 1.091, de 29 de dezembro de 2006. Diário Oficial do Município de Manaus, Poder Executivo, Manaus, AM, 2006.

MANAUS. Lei Orgânica do Município de Manaus, de 05 de abril de 1990. Poder Executivo, Manaus, AM, 1990. Disponível em http://www.leismunicipais.com.br. Acesso em jun. 2009

MANAUS. Projeto de Lei $n^{\circ}$ 087/2009. Câmara Municipal de Manaus. Manaus, AM, 2009.

MESQUITA, O. Manaus: historia e arquitetura (1852-1910). 3ed. Manaus: Valer, 2006.

MONTEIRO, M. Y. Fundação de Manaós: aspectos do panorama histórico-social do antigo Lugar da Barra. Manaus: 1952.

MORSELLO, C. Áreas protegidas públicas e privadas: seleção e manejo. São Paulo: Annablume/FAPESP, 2001.

OLIVEIRA, J. A. Manaus de 1920-1967: a cidade doce e dura em excesso. Manaus: Valer, 2003. 


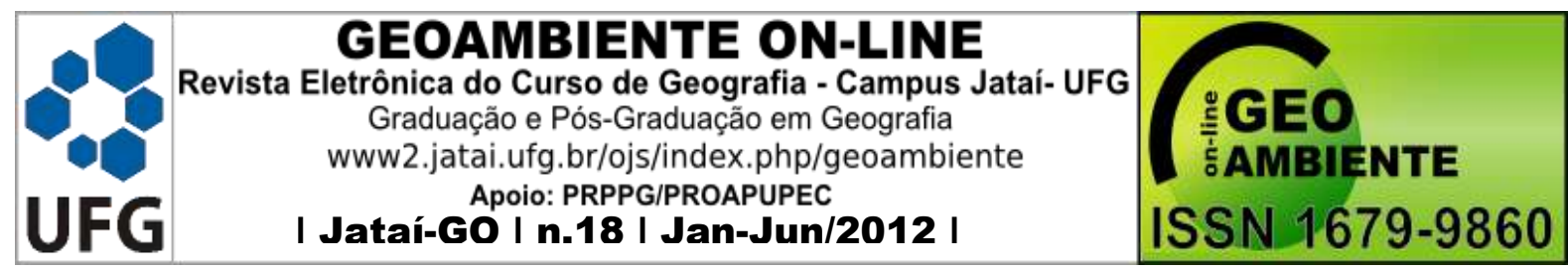

PEREIRA, D. Amazônia insustentável. Zona Franca de Manaus: estudo e análise. 2 ed. Valer: Manaus, 2006.

RIBEIRO FILHO, V. Mobilidade residencial em Manaus: uma análise introdutória. EDUA: Manaus, 1999.

SALATI, E. Modificações da Amazônia nos últimos 300 anos: suas conseqüências sociais e ecológicas. IN: BRITO, S.S. (Org.). Desafio Amazônico: o futuro da civilização dos trópicos. Brasília: Editora da Universidade de Brasília, CNPq, 1990.

SEMMAS - Secretaria Municipal de Meio Ambiente e Sustentabilidade. Relatório Interno Gestão 2005-2008. Manaus: PMM, 2009.

SIPAM - Sistema de Proteção da Amazônia. Estudo do desmatamento na Zona Urbana de Manaus e sua relação com a expansão demográfica. Manaus: CENSIPAM/CTOMN/DAMB, 2005.

VIEIRA, A. F. G. Desenvolvimento e distribuição de voçorocas em Manaus (AM): principais fatores controladores e impactos urbanos-ambientais. (Tese de doutorado em Geografia): Departamento de Geografia. UFSC, 2008. 